\title{
Uncertainty from model structure is larger than that from model parameters in simulating rice phenology in China
}

\author{
Shuai Zhang ${ }^{a}$, Fulu Tao ${ }^{a, c}, *$, Zhao Zhang ${ }^{b}$ \\ ${ }^{a}$ Key Laboratory of Land Surface Pattern and Simulation, Institute of Geographic Sciences \\ and Natural Resources Research, Chinese Academy of Sciences, Beijing 100101, China \\ ${ }^{\mathrm{b}}$ State Key Laboratory of Earth Surface Processes and Resource Ecology, Beijing Normal \\ University, Beijing 100875, China \\ ${ }^{\mathrm{c}}$ Natural Resources Institute Finland (Luke), Fl-00790 Helsinki, Finland. \\ *Correspondance: Fulu Tao. E-mail: taofl@igsnrr.ac.cn
}

\begin{abstract}
Rice models have been widely used in simulating and predicting rice phenology in contrasting climate zones, however the uncertainties from model structure (different equations or models) and/or model parameters were rarely investigated. Here, five rice phenological models/modules (i.e., CERES-Rice, ORYZA2000, RCM, Beta Model and SIMRIW) were applied to simulate rice phenology at 23 experimental stations from 1992 to 2009 in two major rice cultivation regions of China: the northeastern China and the southwestern China. To investigate the uncertainties from model biophysical parameters, each model was run with randomly perturbed 50 sets of parameters. The results showed that the median of ensemble simulations were better than the simulation by most models. Models couldn't simulate well in some specific years despite of parameters optimization, suggesting model structure limit model performance in some cases. The models adopting accumulative thermal time function (e.g., CERES-Rice and ORYZA2000) had better performance in the southwestern China, in contrast, those adopting exponential function (e.g., Beta model and $\mathrm{RCM}$ model) had better performance in the northeastern China. In northeastern China, the contribution of model structure and model parameters to model total variance was, respectively, about $55.90 \%$ and $44.10 \%$ in simulating heading date, and about $75.43 \%$ and $24.57 \%$ in simulating maturity date. In the southwestern China, the contribution of model structure and model parameters to model total variance was, respectively, about $79.97 \%$
\end{abstract}


and $27.03 \%$ in simulating heading date, about $92.15 \%$ and $7.85 \%$ in simulating maturity date. Uncertainty from model structure was the most relevant source. The results highlight that the temperature response functions of rice development rate under extreme climate conditions should be improved based on environment-controlled experimental data.

Keywords: crop model; extreme weather; impacts; rice development rate; uncertainty

\section{Introduction}

Crop phenology is closely related to agricultural system dynamic and crop yield, hence, it is important to understand and predict crop development and phenology (Bradley et al., 1999; Abu-Asab et al., 2001; Zhang et al., 2004; White et al., 2009). Crop phenological models are routinely applied to simulate and predict crop development and phenology (Zhang and Tao, 2013, 2014; Timsina and Humphreys et al., 2006; Palosuo et al., 2011). Although great progress in crop modelling has been made in last decades, crop phenological models have still large uncertainties (Rötter et al., 2011; Zhang and Tao, 2013; Asseng et al., 2013; Bassu et al., 2014; Li et al., 2015). Crop phenological models are various in describing the response of crop development as a function of temperature, daylength and vernalization (Jones et al., 2003; Kropff et at., 1995; Bouman et al., 2001). Some of them adopt an accumulative thermal time function and some of them adopt an exponential function in simulating the response of crop development to temperature. The CERES-Rice, ORYZA2000, Rice Clock Model (RCM), Beta Model and Simulation Model for Rice-Weather relationship (SIMRIW) are widely used, easily accessible and well-documented rice growth simulation models (Matthews et al., 1997; Yin et al., 1997; Mahmood, 1998; Jin et al., 2003; Das et al., 2007; Chen et al., 2008). These models show rice development rate increases with temperature but with different development rates (Zhang and Tao, 2013). Most previous studies try to estimate the optimal parameters of existing models to reduce model errors (Challinor et al., 2005; lizumi et al., 2009; Tao et al., 2009). However, the rice development rate is not only related to model parameters, but also depends largely on model structure (the form of the equation) (He et al., 2014). In fact, because different rice models employ different functions to simulate the response of rice development rate to temperature, the simulated rice development rate varies largely among these models (Zhang and Tao, 2013). To reduce model errors, it is necessary to investigate the roles of model parameters and model structure in causing model errors.

In the present study, we intend to investigate the sensitivity of crop development rate to model biophysical parameters and model structure using the five rice phenological models. We aim to (1) investigate the uncertainty of phenological simulation from model biophysical parameters in each of the five models; $(2)$ investigate the uncertainty of phenological 
simulation from different phenological models (model structure); (3) compare the relative contribution of model structure and model biophysical parameters to model total variance.

\section{Materials and Methods}

\subsection{Observed rice phenology and climate data}

We focused on the single-season rice cultivated in the northeastern China (zone I) and southwestern China (zone II) (Fig. 1). Observed rice phenology data and daily weather data were obtained from 23 national agro-meteorological experiment stations (11 stations in zone I and 12 stations in zone II), managed by China Meteorological Administration (CMA).

For all the stations in zone $\mathrm{I}$, the range of maximum temperature was from $-28.0^{\circ} \mathrm{C}$ to $37.8^{\circ} \mathrm{C}$, with $80 \%$ of the values between $-1.87^{\circ} \mathrm{C}$ and $27.13^{\circ} \mathrm{C}$. The range of minimum temperature was from $-44.1^{\circ} \mathrm{C}$ to $27.2^{\circ} \mathrm{C}$, with $80 \%$ of the values between $-18.9^{\circ} \mathrm{C}$ and 17.0 ${ }^{\circ} \mathrm{C}$. The frequency distribution of temperatures during rice growth season in zone I was shown in Fig. 2. The range of temperatures was from $3^{\circ} \mathrm{C}$ to $31^{\circ} \mathrm{C}$, and the peak value was $21^{\circ} \mathrm{C}$. For all the stations in zone $\mathrm{II}$, the range of maximum temperature was from $-3.4^{\circ} \mathrm{C}$ to $43.2^{\circ} \mathrm{C}$, with $80 \%$ of the values between $12.7^{\circ} \mathrm{C}$ and $33.7^{\circ} \mathrm{C}$. The range of minimum temperature was from $-12.1^{\circ} \mathrm{C}$ to $31.4^{\circ} \mathrm{C}$, with $80 \%$ of the values between $5.6^{\circ} \mathrm{C}$ and $23.7^{\circ} \mathrm{C}$. The range of temperature was from $4{ }^{\circ} \mathrm{C}$ to $35^{\circ} \mathrm{C}$, and the peak value was $26^{\circ} \mathrm{C}$ (Fig. S1).

For each station, the dates of the major phenological events were recorded by local agrotechnicians. The choice of rice cultivars was based on the major cultivar used by local farmers in the investigating year. Rice cultivars were usually renewed for every three to five years (Zhang et al., 2012). Observed rice transplanting date, heading date and maturity date for each station from 1992 to 2009, as well as the datasets of daily and monthly mean temperature, at these stations were used. In this study, the phenological data from 1992 to 2000 at each station were used to calibrate the parameters of all five models and those from 1992 to 2009 were employed to evaluate the models.

\subsection{Descriptions of the rice phenology models}

Five widely used, easily accessible and well-documented rice growth simulation models, i.e. CERES-Rice, ORYZA2000, RCM, Beta Model and SIMRIW, were applied in this study. Each model used different parameters and methods to simulate rice development rate. In order to compare these five models, we unified the growth stage in these models. The stage from transplanting date to heading date was defined as vegetative growth period (VGP); the stage from heading date to maturity date was defined as reproductive growth stage (RGP). The developmental index (DVI) was defined as 0.1 at transplanting, 1.0 at heading and 2.0 at maturity. Therefore, DVI of VGP was from 0.1 to 1.0 , and DVI of RGP was from 1.0 to 2.0. The value of DVI was calculated by summing the developmental rate (DVR) with respect to time: 


$$
D V I_{t}=\sum_{i=0}^{i=t} D V R_{i}
$$

where $D V I_{t}$ is the developmental index at day t, and $D V R_{i}$ is the developmental rate on the i-th day from transplanting. Models are described briefly below.

The CERES-Rice model (Alocija \& Ritchie, 1988; Jones et al., 2003) has been used extensively to simulate rice growth and yield over a wide range of environments, including China (Tao et al., 2008; Xiong et al., 2008). The version we used was a modified version as Li et al. (2015). In this version, daily thermal time (DTT) is used to describe the process of rice development. VGP completes when the accumulation of DTT reaches a threshold (P1); RGP completes when the accumulation of DTT reaches a threshold (P5).The equations can be converted as follows:

$$
\begin{gathered}
D V R=D T T \cdot F D L / P 1 \quad \text { for } \quad 0<D V I \leq 1 \\
D V R=D T T / P 5 \quad \text { for } \quad 1<D V I \leq 2
\end{gathered}
$$

DTT is calculated as follows:

$$
\left\{\begin{array}{l}
D T T_{i}=0 \quad \text { for } \quad T_{\max } \leq T_{\text {base }} \text { or } T_{\min } \geq T_{\text {high }} \\
D T T_{i}=\left(T_{d}-T_{\text {base }}\right) / 24 \quad \text { for } \quad T_{\max }>T_{\text {opt }} \text { or } T_{\min }<T_{\text {base }} \\
D T T_{i}=\left(T_{\max }+T_{\min }\right) / 2-T_{\text {base }} \text { for others }
\end{array}\right.
$$

where $T_{o p t}$ is the optimum temperature, $T_{h i g h}$ is a critical high temperature for crop development, $T_{b a s e}$ is the base temperature. $T_{\min }$ and $T_{\max }$ are the daily minimum and maximum temperatures. $T_{d}$ is hourly temperature. $h$ is the hour of the day. $T_{d}$ is calculated by $T_{\min }$ and $T_{\max }$ :

$$
\begin{aligned}
T_{d}= & \left(T_{\text {min }}+T_{\text {max }}\right) / 2+\left(T_{\max }-T_{\min }\right) / 2 \cdot \sin [3.14 / 12 \cdot h] \\
& \left\{\begin{array}{l}
T_{d}=T_{\text {base }} \text { for } T_{d}<T_{\text {base }} \\
T_{d}=T_{\text {opt }}-\left(T_{d}-T_{o p t}\right) \quad \text { for } \quad T_{d}>T_{\text {opt }}
\end{array}\right.
\end{aligned}
$$

Day length (FDL) is calculated as follows: 


$$
F D L=\left[1+P 2 R / 136 \times\left(D L_{k}-D L_{c}\right)\right]^{-1}
$$

where $D L_{k}$ is daily mean day length. $D L_{c}$ is the critical day length. $P 2 R$ is photoperiod sensitivity parameter.

In the ORYZA2000 (Kropff et al., 1995; Bouman et al., 2001) model, daily increments in developmental time (DTU) is used to describe rice development. VGP completes when the accumulation of DTU reaches a threshold (DVRI); RGP completes when the accumulation of DTU reaches another threshold (DVRR). The equations can be converted as follows:

$$
\begin{gathered}
D V R=D T U \cdot F D L / D V R I \quad \text { for } \quad 0<D V I \leq 1 \\
D V R=D T U / D V R R \quad \text { for } \quad 1<D V I \leq 2
\end{gathered}
$$

DTU is calculated as:

$$
\begin{aligned}
& D T U=\sum_{h=1}^{24}(H D) \\
& \left\{\begin{array}{l}
H D=0 \quad \text { for } \quad T_{d} \leq T_{\text {base }} \text { or } \quad T_{d} \geq T_{\text {high }} \\
H D=\left(T_{d}-T_{\text {base }}\right) / 24 \quad \text { for } \quad T_{\text {base }}<T_{d} \leq T_{\text {opt }} \\
H D=\left[T_{\text {opt }}-\left(T_{d}-T_{\text {opt }}\right) \times\left(T_{\text {opt }}-T_{\text {base }}\right) /\left(T_{\text {high }}-T_{\text {opt }}\right)\right] / 24 \quad \text { for } \quad T_{\text {opt }}<T_{d}<T_{\text {high }}
\end{array}\right.
\end{aligned}
$$

where HD is hourly increments in developmental age. $T_{d}$ is calculated from $T_{\min }$ and $T_{\max }$ as:

$$
T_{d}=\left(T_{\min }+T_{\max }\right) / 2+\left(T_{\max }-T_{\min }\right) / 2 \cdot \cos [0.2618(h-14)]
$$

FDL is calculated as:

$$
F D L=1-\left(D L_{k}-D L_{c}\right) \times P P S E
$$

where PPSE is photoperiod sensitivity parameter.

The RCM $(G a o, 1992)$ describes a base model covering the entire stage of rice development and uses daily mean temperature and day length data to calculate rice daily development rate. 


$$
\begin{gathered}
D V R=\exp (k)\left(\frac{T-T_{\text {base }}}{T_{\text {opt }}-T_{\text {base }}}\right)^{P}\left(\frac{T_{\text {high }}-T}{T_{\text {high }}-T_{\text {opt }}}\right)^{Q} \exp \left[G\left(D L_{k}-D L_{c}\right)\right] \\
\left\{\begin{array}{lll}
T=T_{\text {base }} & \text { for } & T<T_{\text {base }} \\
T=T_{\text {high }} & \text { for } & T>T_{\text {high }}
\end{array}\right. \\
D L_{k}=D L \text { for } \quad D L_{k}<D L_{c}
\end{gathered}
$$

where $T$ is the daily mean temperature, $\mathrm{k}, \mathrm{P}, \mathrm{Q}$ and $\mathrm{G}$ are empirical constants, during $\mathrm{RGP}, \mathrm{G}=0$ is assumed.

The nonlinear Beta model (Yin et al., 1995; Yin and Kropff, 1996) is described as:

$$
\begin{gathered}
D V R=\exp (\mu)\left(T-T_{\text {base }}\right)^{\alpha}\left(T_{\text {high }}-T\right)^{\beta} \cdot D L_{k}^{\delta}\left(24-D L_{k}\right)^{\varepsilon} \quad \text { for } \quad 0<D V I \leq 1 \\
D V R=\exp (\mu)\left(T-T_{\text {base }}\right)^{\alpha}\left(T_{\text {high }}-T\right)^{\beta} \quad \text { for } \quad 1<D V I \leq 2
\end{gathered}
$$

where $\mu, \alpha, \beta, \delta$ and $\varepsilon$ are empirical constants.

In the SIMRIW (Horie, 1995), the phenological development is described by using the Developmental Index (DVI). DVR from transplanting to heading $(0<D V I<1)$ is calculated as follows:

$$
\left\{\begin{array}{l}
D V R=\left\{1-\exp \left[B\left(D L_{k}-D L_{c}\right)\right]\right\} / G_{v}\left\{1.0+\exp \left[-A\left(T-T_{h}\right)\right]\right\} \quad \text { for } \quad D L_{k} \leq D L_{c} \\
D V R=0 \text { for } D L_{k}>D L_{c}
\end{array}\right.
$$

where $T_{h}$ is the temperature at which DVR is half the maximum rate at the optimum temperature $\left({ }^{\circ} \mathrm{C}\right), G_{v}$ is the minimum number of days required for heading, $\mathrm{A}$ and $\mathrm{B}$ are empirical constants.

The following equation is used to describe the rate of rice development from heading to maturity $(1<D V I \leq 2)$

$$
D V R=\left\{1-\exp \left[-K_{r}\left(T-T_{c r}\right)\right]\right\} / G_{r}
$$

where $G_{r}$ is the minimum number of days for grain-filling period $K_{r}$ and $T_{c r}$ are empirical constants. 


\subsection{Parameter perturbation}

To better understand the uncertainty from model parameters, the runif function in $\mathrm{R}$ software was used to randomly perturb model parameters. The parameters of the five models were calibrated by minimizing the following cost function:

$$
J(x)={ }_{i}^{n}\left(o b s_{i} m(x)\right)^{2}
$$

where $\mathrm{x}$ is the parameters in rice phenology models. obs $\mathrm{s}_{\mathrm{i}}$ is the $i^{\text {th }}$ measurement. $n$ is the total number of measurements. The cost function presents the mismatches between observations and predictions. A global optimization method named SCE-UA (shuffled complex evolution method) was applied to minimize the cost function (Duan et al., 1994) with Matlab software. 50 sets of model parameters were generated by random sampling method with an assumption that each parameter had a Gaussian distribution. For each parameter, the mean value of the Gaussian distribution was the calibrated value of the parameter. The variance of the Gaussian distribution was the uncertainty of the parameter. Then each of the five phenological models was run with its respective 50 sets of perturbed parameters. One set of optimal parameters and range of 50 sets of perturbed parameters were shown in Table 1.

\section{4. uncertainties from model structure and model parameters}

The uncertainty from model structure was investigated by comparing the simulations using each of the five crop models with its respective one set of optimal parameters. The uncertainty from model parameters was investigated by comparing the simulations with one set of optimal parameters and 50 sets of perturbed parameters. A super-ensemble simulation was conducted using the five models with their respective 50 sets of perturbed parameters to investigate the uncertainties from both model structure and model parameters.

\subsection{Contributions of model structure and model parameters to model total variance}

Uncertainty of simulation was used to compare the simulation to observation. As Wallach et al. (2016), we used the distribution of $y-\hat{f}(X ; \hat{\theta})$ to define the uncertainty: $y$ is predictand, $\hat{f}$ is the applied model structure, $X$ is the input of the model, $\hat{\theta}$ is model parameter. $\hat{f}$ presents the fixed model. In order to get the contribution of structural uncertainty, we averaged parameters of each model and then calculated the variance 
among different models. To obtain the contribution of parameter uncertainty, we calculated the variance of the simulations generated by each model with 50 sets of perturbed parameters and then averaged the variance among all the models. The two parts of model variance were estimated using the simulations with the five models and their respective 50 sets of parameters. Then, the estimation of $\sigma_{\tau}^{2}$ (structure uncertainty) and $\sigma_{\theta}^{2}$ (parameter uncertainty) was deemed as the problem of variance (Scheffé, 1959; Wallach et al., 2016).

\subsection{Analyses}

Uncertainties from crop models were evaluated by comparing ensemble simulations with observations. The median of the individual model simulations was used to compare with observations. We evaluated the accuracy of models by calculating the model bias (Bias), root mean square error (RMSE) and Pearson correlation coefficients $(r$ ) between the observed and simulated values for both heading date and maturity date. The mismatch between simulations and observations was reduced when the suitable parameters were found. In some cases, performance of models would not be improved by model parameter calibrations. We assume these errors should be largely ascribed to incorrect model structure. Errors not related to model parameters were identified as uncertainties from model structure.

\section{Results}

\subsection{Uncertainties from model structure}

Uncertainty from model structure was investigated by comparing the model simulations using each of the five models with its respective one set of optimal parameters. In zone I, with one set of optimal parameters, the highest development rate occurred when temperature approached about $30^{\circ} \mathrm{C} \mathrm{(Fig.} \mathrm{3).} \mathrm{For} \mathrm{heading} \mathrm{date,} \mathrm{the} \mathrm{simulated} \mathrm{highest}$ development rate was about 0.022 by CERES-Rice and ORYZA2000, and $0.016,0.015$, and 0.017 by RCM, Beta model, and SIMRIW, respectively (Fig. 3a). For maturity date, the simulated highest development rate was $0.030,0.037,0.026,0.021$, and 0.023 by CERESRice, OYRZA2000, RCM, Beta Model, and SIMRIW, respectively (Fig. 3b). The RMSEs ranged from 6.09 to 6.70 days with $r$ from 0.27 to 0.30 . RCM model got the least RMSE among all the five models, although it underestimated heading date by 1.89 days. The performance of CERES-Rice and ORYZA2000 was similar in some statistics (Fig. 3, Table 2). The five phenological models with their respective one set of optimal parameters could simulate rice heading date well. However the large errors were found for simulations of heading dates in some specific years (Fig. 4, Fig. S3). For example, in zone I, all models failed to simulate heading date well in 1993, 1998 and 2009 (Fig. 4). CERES-Rice overestimated heading date while other models underestimated heading date. Simulations of maturity date by the five 
models were quite different. The RMSEs ranged from 4.33 to 9.12 days (Table 2). All five models got a larger $r$ in simulating maturity date than in simulating heading date (Table 2). RCM, Beta models and SIMRIW got a smaller RMSE in simulating maturity date than in simulating heading date (Table 2).

In zone II, the RMSEs ranged from 7.08 to 8.60 days. CERES-Rice got the least RMSE among all the five models. The bias of simulation of CERES-Rice was 0.20 days, with $r$ ranging from 0.80 to 0.84 (Table 2). For heading date, with one set of optimal parameters, the simulated highest development rate was $0.020,0.019,0.014,0.016$, and 0.017 by CERESRice, OYRZA2000, RCM, Beta Model and SIMRIW, respectively (Fig. S2a). For maturity date, with one set of parameters, the simulated highest development rate was $0.034,0.040$, $0.034,0.033$, and 0.039 by CERES-Rice, OYRZA2000, RCM, Beta Model and SIMRIW, respectively (Fig. S2b). For single-season rice cultivated in zone II, the heading date was overestimated in 1992. In 1999 and 2001, RCM and Beta model underestimated heading date. For single-season rice cultivated in zone II, RMSEs in simulating maturity date ranged from 4.256 to 5.42 days (Table 2). All the models overestimated heading date in 1994 (Fig. S3).

\subsection{Uncertainties from model parameters}

Each of the five models was driven by its respective 50 sets of perturbed parameters to investigate the uncertainty from model parameters. The median value of ensemble simulations using each model with its respective 50 sets of perturbed parameters was used to compare with the observation (Table 2). For heading date, the statistics (RMSE, $r$, Bias) of the ensemble simulations were close to those of the corresponding simulation with one set of optimal parameters. For maturity date, the ensemble simulations with 50 sets of perturbed parameters were better.

In zone I, with 50 sets of perturbed parameters (Fig. 5), for heading date, the simulated highest development rate was 0.022-0.025, 0.022-0.024, 0.015-0.016, 0.014-0.016, and 0.017-0.018 by CERES-Rice, OYRZA2000, RCM, Beta Model, and SIMRIW, respectively (Fig. $5 a)$. For maturity date, the simulated highest development rate was $0.030-0.032,0.036$ 0.040, 0.024-0.028, 0.020-0.025, and 0.021-0.024 by CERES-Rice, OYRZA2000, RCM, Beta Model, and SIMRIW, respectively (Fig. 5b). Simulations from CERES-Rice model with one set of optimal parameters close to observation except the simulations in 1993, 1998 and 2009

(Fig. 4). There were still some errors in heading date and maturity date simulations even using the ensemble simulations with 50 sets of perturbed parameters, (Fig. 6a). In 1993, 1994, 1995, 1999, 2000, and 2009, CERES-Rice couldn't simulate rice maturity date reasonably well (Fig. 6a). Likewise, ORYZA2000 simulated heading date better than maturity date (Fig. 6b). In 1993, 1994, 2000, 2005, and 2008, the RMSE of maturity date simulation was larger. All the models underestimated heading date. Beta model has good performance 
in maturity date simulations (Fig. 6c, d). Ensemble simulations of Beta model and ORYZA2000 with their respective 50 sets of perturbed parameters performed better, suggesting model parameters optimization could improve the performance of the two models in simulating maturity date. However, the model errors in simulating heading dates couldn't be improved obviously by optimizing model parameters. SIMRIW performed well on simulating heading date and maturity date (Fig. 6e).

In zone II, for heading date, with 50 sets of parameters, the simulated highest development rate was 0.019-0.021, 0.018-0.019, 0.013-0.015, 0.015-0.018 and 0.015-0.017 by CERES-Rice, OYRZA2000, RCM, Beta Model, and SIMRIW, respectively (Fig. S4a). For maturity date simulation, the simulated highest development rate was 0.032-0.035, 0.038$0.041,0.030-0.036,0.031-0.035$, and $0.036-0.040$ by CERES-Rice, OYRZA2000, RCM, Beta Model, and SIMRIW, respectively (Fig. S4b). The ensemble simulations with 50 sets of perturbed parameters also reduced model errors slightly, in comparison with the simulations with one set of optimal parameters. For example, the CERES-Rice model with its 50 sets of perturbed parameters overestimated heading dates from 1992 to 1996 (Fig. S5a). ORYZA2000 and RCM model were improved by the ensemble simulations (Fig. S5b, c). The results from all the five models indicated that ensemble simulations with their respective 50 sets of perturbed parameters could only improve model performance slightly if the models were well calibrated (Fig. S5). In other words, the uncertainty from model parameters should be less than that from model structure.

\subsection{Super-ensemble simulations with the five models and 50 sets of perturbed parameters}

The median of super-ensemble simulations with the five models and their respective 50 sets of perturbed parameters were better than simulations by most of the models with their respective one set of optimal or 50 sets of perturbed parameters, for both heading date and maturity date (Table 2).

In zone I, for heading date, all models had similar simulations (Fig. 7). SIMRIW model got the best estimates among all the five models. All five models underestimated heading date. RCM and Beta model underestimated more than other models, which may be ascribed to model structure because RCM and Beta models have similar model structure (exponential function). For maturity date, the simulations with the five models were quite different. ORYZA2000 had the best estimates among the five models. RCM overestimated maturity date most.

In zone II, ORYZA2000 got the best estimate of heading date, RCM and Beta model underestimated heading date (Fig. S6). Most models overestimated maturity date before 1998 , the simulation of maturity date was better after 1998 than before 1998 . The super- 
ensemble simulation with the five models and their respective 50 sets of perturbed parameters could not improve the simulations in several years.

\subsection{Contributions of model structure and model parameters to model variance}

Share of the model total variance from model structure and model parameters in simulating heading date and maturity date was investigated. In zone I, the results showed that the contribution of model structure to model total variance was $26.21 \%$ to $93.98 \%$ in simulating heading date (Fig. 8a), and $38.97 \%$ to $97.31 \%$ in simulating maturity date (Fig. 8 b). In contrast, the contribution of model parameters was $6.02 \%$ to $73.79 \%$ in simulating heading date (Fig. 8a), and $2.69 \%$ to $61.03 \%$ in simulating maturity date (Fig. 8b). In zone II, the results showed that the contribution of model structure to model total variance was $71.63 \%$ to $86.73 \%$ in simulating heading date (Fig. S7a), and $90.14 \%$ to $97.61 \%$ in simulating maturity date (Fig. S7b). In contrast, the contribution of model parameters was $15.36 \%$ to $28.37 \%$ in simulating heading date (Fig. S7a), and $2.39 \%$ to $9.52 \%$ in simulating maturity date (Fig. S7b).

\section{Discussion}

Robust model parameterization based on observed data is essential and pre-requirement for model applications. To quantify the uncertainties in model simulation and climate change impact assessment, ensemble simulations have been widely recommended (Tao et al., 2009a, b, Asseng et al., 2013, Martre et al., 2015). The ensemble simulations from 27 wheat models indicated that the median values of ensemble simulations had better performance than any individual simulations (Asseng et al., 2013; Martre et al., 2015). Our results also indicated that the median values of ensemble simulations were more accurate than most individual simulations (Table 2). The possible explanation is that the errors in the ensemble members tend to compensate each other (Martre et al. 2015).

The ensemble simulations could be obtained by using individual model with multiple sets of model parameters (Tao et al., 2009a) or multiple models (Palosuo, et al., 2011; Asseng et al., 2013; Bassu et al., 2014; Martre et al., 2015; Li et al., 2015) or multiple models with multiple sets of model parameters called the super-ensemble simulation (Wallach et al., 2016). The super-ensemble simulations method accounts for uncertainties from both model structure and model parameters. In this study, the contribution of model structure was much larger than that of model parameters to model total variance. One of the major problems with the current models was that crop development rate under extreme climate events were not well formulated (Lobell et al., 2012; Zhang and Tao, 2013; Asseng et al., 2015). These cause models not to be able to simulate crop phenology well under extreme climate conditions such as extreme high or low temperature events. In addition, we found the models with similar mechanisms or structure may get similar simulations. The model errors couldn't be improved much with multiple sets of parameters in some specific year. 
For example, all the models failed to simulate rice phenology accurately in 1993, 1998 and 2009 without reference to parameter values. There are two peak values for frequency distribution of temperatures in 1993, 1998 and 2009 (Fig. 9). It indicated that model performance was limited under exceptional temperature.

In fact, the model errors were intrinsically determined by the temperature response functions in the models. The development rate in most models increases when the observed temperature is lower than the optimal temperature and it declines when the observed temperature is larger than the optimal temperature. This response of development rate to temperature is supported by many previous studies (Parent et al., 2010)). However the temperature response function in SIMRIW is quite different. It has constant development rates when observed temperature is larger than $20^{\circ} \mathrm{C}$ and an abrupt decline of development rate when observed temperature is larger than $35^{\circ} \mathrm{C}$. It is difficult to conclude which kind of temperature response function is true. Therefore, the uncertainty of model structure should be reduced by elaborating the temperature response function based on environmentcontrolled experimental data (Asseng et al., 2015).

The error of model parameters is another source of model uncertainty. Martre et al. (2015) indicated that several individual models had small errors for end-season variables (e.g. grain yield) and large errors for in-season variables (e.g. leaf area index). In some cases, crop models may get the right answer for the wrong reasons (Martre et al, 2015). It is mainly because different variables are controlled by different parameters (Wallach, 2011). Therefore, it is important to calibrate different parameters of crop model using multiple observations. For example, cardinal temperatures are considered some important parameters for crop phenology simulations. Sánchez et al (2014) suggested that cardinal temperatures are various in different crop phenology simulations for different cultivars and regions. In order to improve the performances of crop models, it is necessary to calibrate cardinal temperatures in models in advance.

Besides the limitation caused by climate condition, the number of observations used in calibration will influence the result. The contribution provided by model parameters will changed by the different input data. Only northeastern China and southwestern China were considered in this study. In other regions the result may be different. Also, parameter correlation was not considered in our study, which will influence the uncertainty distribution.

\section{Conclusions}

Uncertainties associated with the five rice phenological models/modules in simulating and predicting rice phenology in two major rice production regions of China were investigated. In conclusion, 
(1) All models with one set of optimal parameters had a general good performance in simulating rice heading date. In northeastern China, The RMSEs of the five models ranged from 6.09 to 6.70 days. For maturity date, the performance of each model was various. Beta model got the smallest RMSE of 4.33 days, among the five models. In southwestern China, the RMSEs of the five models ranged from 7.08 to 8.60 days for heading date. The RMSEs of the five models ranged from 4.89 to 5.42 days for maturity date.

(2) Simulations of heading and maturity date captured observations better when the multiple sets of perturbed parameters were used. However, some models cann't capture observation well in some specific years without reference to parameter values, which indicated that model structure limit model performance in some cases.

(3) The models adopting temperature accumulation function (i.e., CERES-Rice and ORYZA2000) had better performance in zone II than in zone I. While the models adopting exponential function (i.e., Beta model and RCM model) had better performance in zone I than in zone II.

(4) Uncertainty from model structure was generally larger than that from model parameters.

(5) In zone I, the contribution of model structure and model parameter to model total variance was about $55.90 \%$ and $44.10 \%$, respectively, in simulating heading date; the contribution of model structure and model parameter to model total variance was about

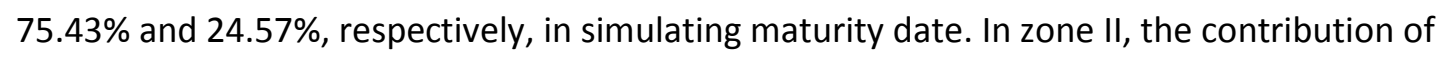
model structure and model parameter to model total variance was about $79.97 \%$ and $27.03 \%$, respectively, in simulating heading date; the contribution of model structure and model parameter to model total variance was about $92.15 \%$ and $7.85 \%$, respectively, in simulating maturity date.

\section{Acknowledgments}

This study is supported by the National Key Research and Development Program of China (Project No. 2016YFD0300201), the National Science Foundation of China (Project Nos. 31561143003 and 41571088), and partly by FACCE MACSUR project through the Finnish Ministry of Agriculture and Forestry. The phenological and climate data used are from the Chinese Meteorological Administration.

\section{References}

Abu-Asab, M.S., Peterson, P.M., Shetler, S.G., Orli, S.S., 2001. Earlier plant flowering in spring as a response to global warming in the Washington, DC, area. 
Biodivers. Conserv. 10, 597-612.

Alocija, E.C., Ritchie, J.T., Upland rice simulation and its use in multicriteria optimization, in: International Benchmark Sites Network for Agrotechnology Transfer, University of Hawaii, Hawaii, 1988, 96.

Asseng, S., Ewert, F., Martre, P., Rötter, R.P., Lobell, D.B., Cammarano, D., Kimball, B.A., Ottman, M.J., Wall, G.W., White, J.W., 2015. Rising temperatures reduce global wheat production. Nature Climate Change 5, 37-64.

Asseng, S., Ewert, F., Rosenzweig, C., Jones, J.W., Hatfield, J.L., Ruane, A.C., Boote, K.J., Thorburn, P.J., Rötter, R.P., Cammarano, D., 2013. Uncertainty in simulating wheat yields under climate change. Nature Climate Change 3, 827832.

Bassu, S., Nadine, B., Durand, J.L., Boote, K., Lizaso, J., Jones, J.W., Rosenzweig, C., Ruane, A.C., Adam, M., Baron, C., 2014. How do various maize crop models vary in their responses to climate change factors? Global. Change. Biol. 20, $2301-2320$.

Bouman, B.A.M., Kropff, M.J., Tuong, T.P., ORYZA2000: Modeling lowland rice, IRRI and Wageningen University, Los Banos, 2001.

Bradley, N.L., Leopold, A.C., Ross, J., Huffaker, W., 1999. Phenological changes reflect climate change in Wisconsin. P. Natl. Acad. Sci. Usa. 96, 9701-9704.

Challinor, A.J., Wheeler, T.R., Craufurd, P.Q., Slingo, J.M., 2005. Simulation of the impact of high temperature stress on annual crop yields. Agric. Forest. 
Meteorol. 135, 180-189.

Chen, J., Xu, Z., Lin, J., Li, L., Wang, J., 2008. Decision Making Supporting System on Rate of Fertilization of Rice in Southeast Coast Areas of Fujiang Province Based on RCSODS. Chinese Journal of agrometeorology 29, 71-74.

Das, L., Lohar, D., Sadhukhan, L., Khan, S.A., Saha, A., Sarkar, S., 2007. Evaluation of the performance of ORYZA2000 and assessing the impact of climate change on rice production in Gangetic West Bengal. Journal of Agrometeorology 9, 110.

Duan, Q., Sorooshian, S., Gupta, V.K., 1994. Optimal use of the SCE-UA global optimiztion method for calibrating watershed models. J. Hydrol. 158, 265-284.

Gao, L., Jin, Z., Huang, Y., Zhang, L., 1992. Rice clock model - a computer model to simulate rice development. Agric. Forest. Meteorol. 60, 1-16.

He, L., Chen, J.M., Liu, J., Mo, G., Bélair, S., Zheng, T., Wang, R., Chen, B., Croft, H., Arain, M.A., 2014. Optimization of water uptake and photosynthetic parameters in an ecosystem model using tower flux data. Ecol. Model. 294, 94-104.

Horie, T., Nakagawa, H., Ceneno, H.G.S., Kropff, M.,, The rice crop simulation model SIMRIW and its testing., in: R.B. Matthews, Kropff, M.J., Bachelet, D. (Eds) (Ed.) Modeling the Impact of Climate Change on Rice Production in Asia., CAB Int, 1995, pp. 51-66.

Iizumi, T., Yokozawa, M., Nishimori, M., 2009. Parameter estimation and uncertainty analysis of a large-scale crop model for paddy rice: Application of a Bayesian 
approach. Agricultural and Forest Meteorology 149, 333-348.

Jin, Z., Shi, C., Ge, D., Gao, L., Yang, X., Xue, Z., Lu, X., MeiHua, D., 2003. A RCSODS-based Simulation Model for N Fertil izer Appl ication in Precision Farming for Direct-seeding Rice. Acta agronomica sinica 29, 353-359.

Jones, J.W., G, H., H, P.C., J, B.K., D, B.W., A, H.L., W, W.P., U, S., J, G.A., T, R.J., 2003. The DSSAT cropping system model. Eur. J. Agron. 18, 235-265.

Kropff, M.J., Matthews, R.B., Van Laar, H.H., Ten Berge, H.F.M., The rice model ORYZA1 and its testing, CABI in association with IRRI Los Banos, Philippines, 1995.

Li, T., Hasegawa, T., Yin, X., Zhu, Y., Boote, K., Adam, M., Bregaglio, S., Buis, S., Confalonieri, R., Fumoto, T., Gaydon, D., Marcaida, M., Nakagawa, H., Oriol, P., Ruane, A.C., Ruget, F., Singh, B., Singh, U., Tang, L., Tao, F., Wilkens, P., Yoshida, H., Zhang, Z., Bouman, B., 2015. Uncertainties in predicting rice yield by current crop models under a wide range of climatic conditions. Global. Change. Biol. 21, 1328-1341.

Lobell, D.B., Sibley, A., Ortiz-Monasterio, J.I., 2012. Extreme heat effects on wheat senescence in India. Nature Clim. Change 2, 186-189.

Mahmood, R., 1998. Air temperature variations and rice productivity in Bangladesh: a comparative study of the performance of the YIELD and the CERES-Rice models. Ecol. Model. 106, 201-212.

Martre, P., Wallach, D., Asseng, S., Ewert, F., Jones, J.W., Rötter, R.P., Boote, K.J., 
Ruane, A.C., Thorburn, P.J., Cammarano, D., 2015. Multimodel ensembles of wheat growth: many models are better than one. Global. Change. Biol. 21, 911925.

Matthews, R.B., Kropff, M.J., Horie, T., Bachelet, D., 1997. Simulating the impact of climate change on rice production in Asia and evaluating options for adaptation. Agr. Syst. 54, 399-425.

Palosuo, T., Kersebaum, K.C., Angulo, C., Hlavinka, P., Moriondo, M., Olesen, J.E., Patil, R.H., Ruget, F., Rumbaur, C., Takáč, J., 2011. Simulation of winter wheat yield and its variability in different climates of Europe: A comparison of eight crop growth models. Eur. J. Agron. 35, 103-114.

Parent, B., Turc, O., Gibon, Y., Stitt, M., Tardieu, F., 2010. Modelling temperaturecompensated physiological rates, based on the co-ordination of response to temperature of developmental processes. J. Exp. Bot. 61, 2057-2069.

Rotter, R.P., Carter, T.R., Olesen, J.E., Porter, J.R., 2011. Crop-climate models need an overhaul. Nature Climate Change 1, 175-177.

Sánchez, B., Rasmussen, A., Porter, J.R., 2014. Temperature and the growth and development of maize and rice: a review. Global. Change. Biol. 20, 408-417.

Scheffé, H., 1959. The Analysis of Variance. John Wiley \& Sons, New York.

Tao, F., Yokozawa, M., Liu, J., Zhang, Z., 2008. Climate-crop yield relationships at provincial scales in China and the impacts of recent climate trends. Climate Res. 38, 83-94. 
Tao, F., Yokozawa, M., Zhang, Z., 2009a. Modelling the impacts of weather and climate variability on crop productivity over a large area: A new process-based model development, optimization, and uncertainties analysis. Agric. Forest. Meteorol. $149,831-850$.

Tao, F, Zhang, Z., Liu, J., 2009b. Modeling the Impacts of Weather and Climate Variability on Crop Productivity over a Large Area: A New Super-ensemblebased Probabilistic Projection. Agric. Forest. Meteorol. 149, 1266-127.

Timsina, J., Humphreys, E., 2006. Performance of CERES-Rice and CERES-Wheat models in rice-wheat systems: A review. Agr. Syst. 90, 5-31.

Wallach, D., 2011. Crop Model Calibration: A Statistical Perspective. Agron. J. 103, $1144-1151$.

Wallach, D., Nissanka, S.P., Karunaratne, A.S., Weerakoon, W.M.W., Thorburn, P.J., Boote, K.J., Jones, J.W., 2016. Accounting for both parameter and model structure uncertainty in crop model predictions of phenology: A case study on rice. Eur. J. Agron. http://dx.doi.org/10.1016/j.eja.2016.05.013

White, M.A., de Beurs, K.M., Didan, K., Inouye, D.W., Richardson, A.D., Jensen, O.P., O'Keefe, J., Zhang, G., Nemani, R.R., van Leeuwen, W.J.D., Brown, J.F., de Wit, A., Schaepman, M., Lin, X.M., Dettinger, M., Bailey, A.S., Kimball, J., Schwartz, M.D., Baldocchi, D.D., Lee, J.T., Lauenroth, W.K., 2009. Intercomparison, interpretation, and assessment of spring phenology in North America estimated from remote sensing for 1982-2006. Global. Change. Biol. 
$15,2335-2359$.

Xiao, G., Zhang, Q., Yao, Y., Zhao, H., Wang, R., Bai, H., Zhang, F., 2008. Impact of recent climatic change on the yield of winter wheat at low and high altitudes in semi-arid northwestern China. Agric. Ecosyst. Environ. 127, 37-42.

Yin, X., Kropff, M.J., 1996. Use of the Beta function to quantify effects of photoperiod on flowering and leaf number in rice. Agric. Forest. Meteorol. 81, 217-228.

Yin, X., Kropff, M.J., Horie, T., Nakagawa, H., Centeno, H.G.S., Zhu, D., Goudriaan, J., 1997. A model for photothermal responses of flowering in rice .1. Model description and parameterization. Field. Crop. Res. 51, 189-200.

Yin, X., Kropff, M.J., McLaren, G., Visperas, R.M., 1995. A nonlinear model for crop development as a function of temperature. Agric. Forest. Meteorol. 77, 1-16.

Zhang, S., Tao, F., 2013. Modeling the response of rice phenology to climate change and variability in different climatic zones: Comparisons of five models. Eur. J. Agron. 45, 165-176.

Zhang, S., Tao, F., Zhang, Z., 2014. Rice reproductive growth duration increased despite of negative impacts of climate warming across China during 1981-2009. Eur. J. Agron. 54, 70-83.

Zhang, T., Huang, Y., Yang, X., 2013. Climate warming over the past three decades has shortened rice growth duration in China and cultivar shifts have further accelerated the process for late rice. Global. Change. Biol. 19, 563-570.

Zhang, X., Friedl, M.A., Schaaf, C.B., Strahler, A.H., 2004. Climate controls on 
vegetation phenological patterns in northern mid- and high latitudes inferred from MODIS data. Global. Change. Biol. 10, 1133-1145. 


\section{Figure caption:}

Fig.1. Locations of the agro-meteorological experiment stations and the study area in this study.

Fig.2. Frequency distribution of temperatures during vegetative growing period (a) and reproductive growing period (b) in the zone I.

Fig 3. Relationship between rice development rate and temperature in the five models with one set of optimal parameters in zone I. (a) heading date simulated by each of the five models with its respective one set of optimal parameters; (b) maturity date simulated by each of the five models with its respective one set of optimal parameters.

Fig.4. Simulated rice heading dates and maturity dates by the five models with their respective one set of parameters in zone I.

Fig.5. Relationship between rice development rate and temperature for the five models with 50 sets of parameters in zone I. (a) heading date simulated by the five models with their respective 50 sets of parameters; (b) maturity simulated by the five models with their respective 50 sets of parameters.

Fig.6. Simulated rice heading dates and maturity dates by the (a) CERES-Rice, (b) ORYZA2000, (c) RCM, (d) Beta Model, (e) SIMRIW with 50 sets of parameters in zone I. Fig.7. Simulated rice heading dates and maturity dates by the five models with their respective 50 sets of perturbed parameters in zone $\mathrm{I}$.

Fig.8. Share of the model total variance from model structure and model parameters in simulating rice heading date (a) and maturity date (b) in zone I.

Fig.9. Frequency distribution of temperatures in 1993, 1998, and 2009 during rice growing period in zone I. 


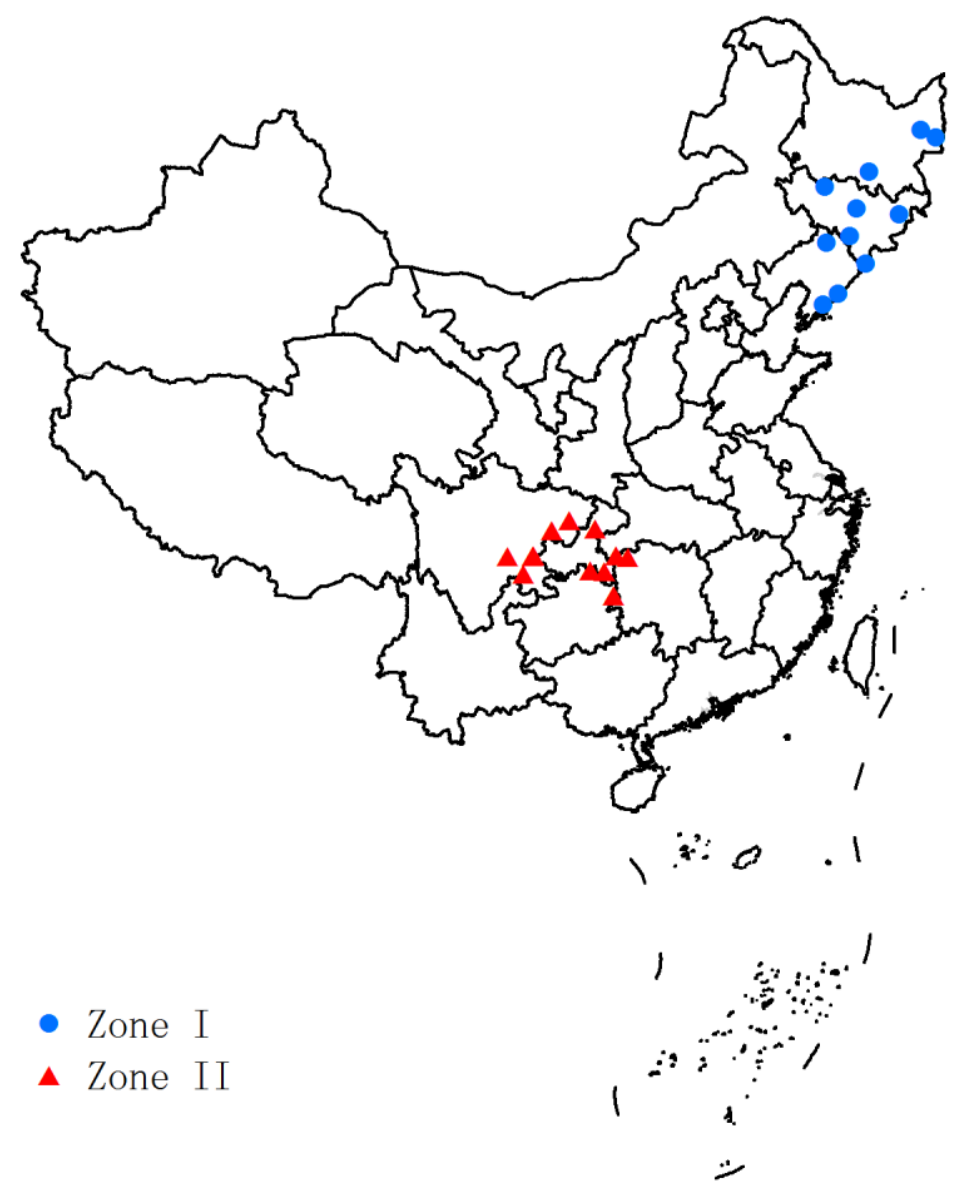

Fig.1. Locations of the agro-meteorological experiment stations and the study area in this study. 


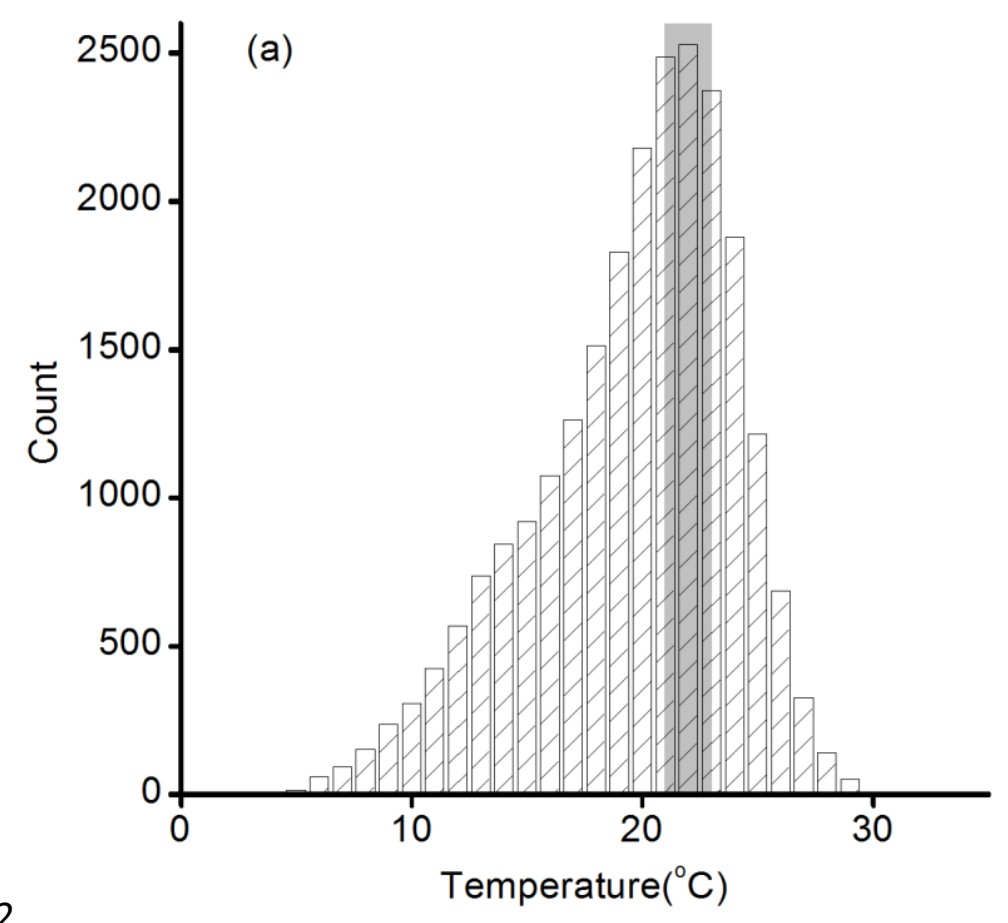

Figr-2

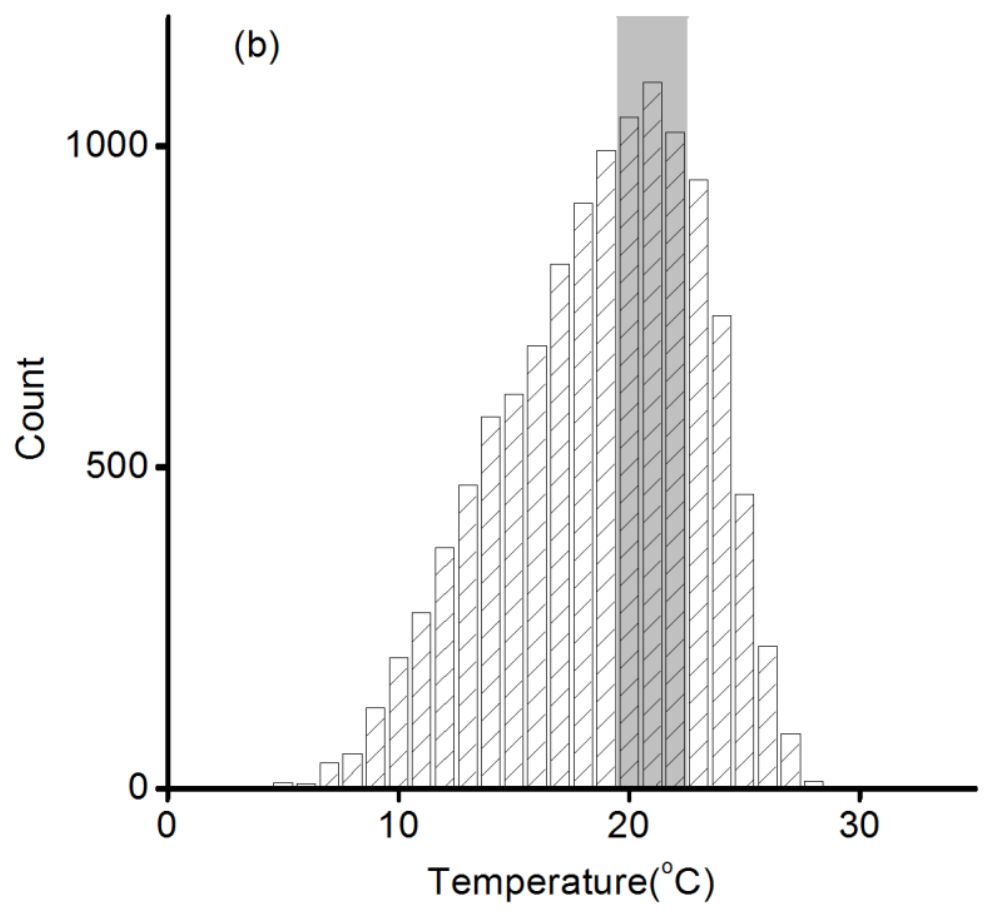

Fig.2. Frequency distribution of temperatures during vegetative growing period (a) and reproductive growing period (b) in the zone I. 


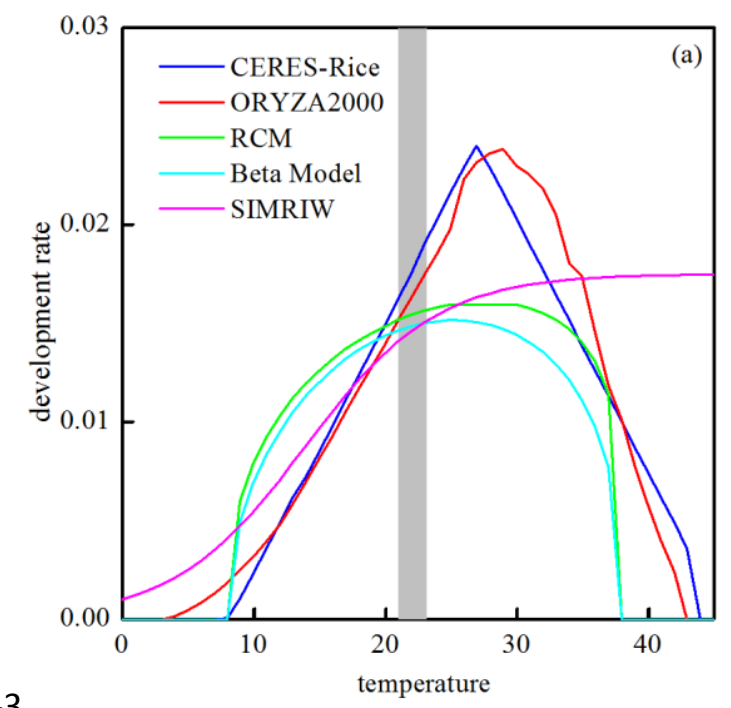

Figr-3

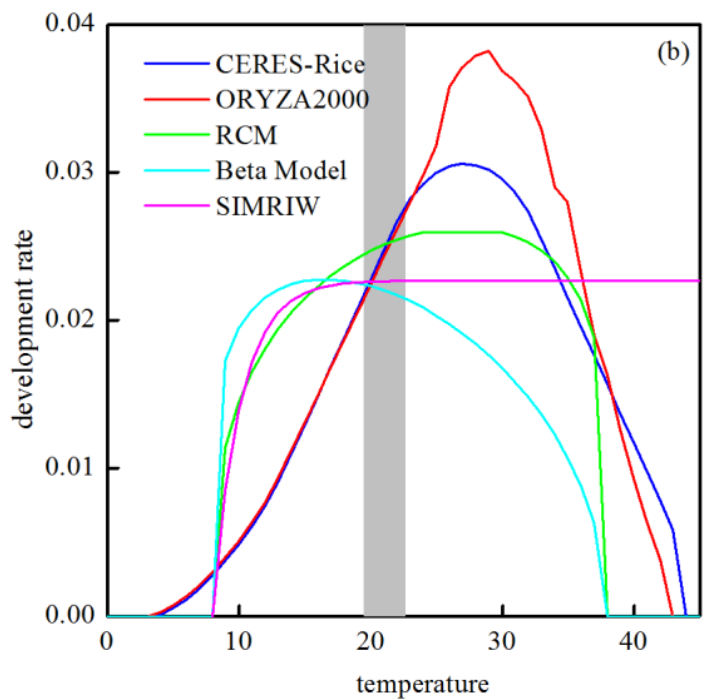

Fig 3. Relationship between rice development rate and temperature in the five models with one set of optimal parameters in zone I. (a) heading date simulated by each of the five models with its respective one set of optimal parameters; (b) maturity date simulated by each of the five models with its respective one set of optimal parameters. 
Figr-4

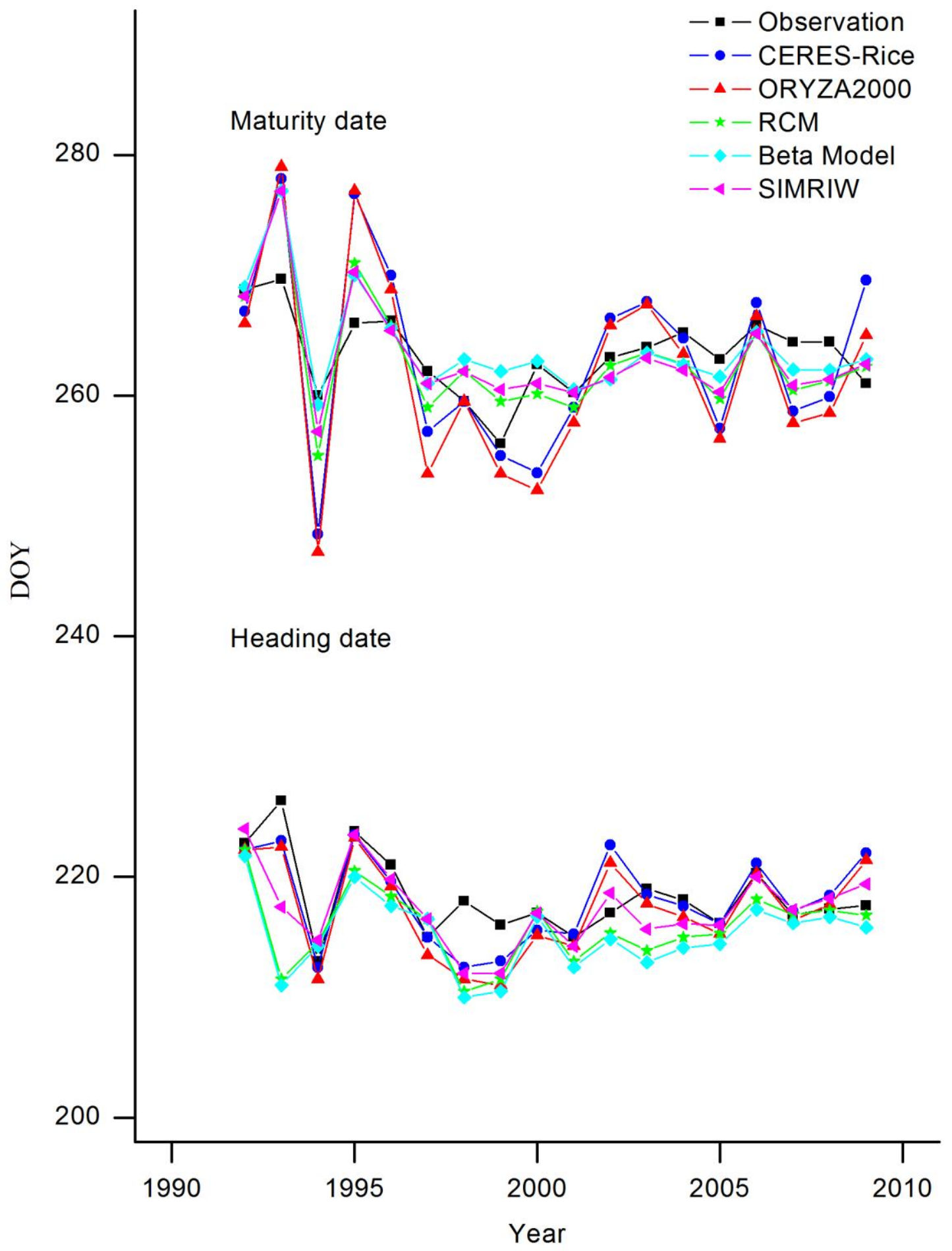

Fig.4. Simulated rice heading dates and maturity dates by the five models with their respective one set of parameters in zone I. 


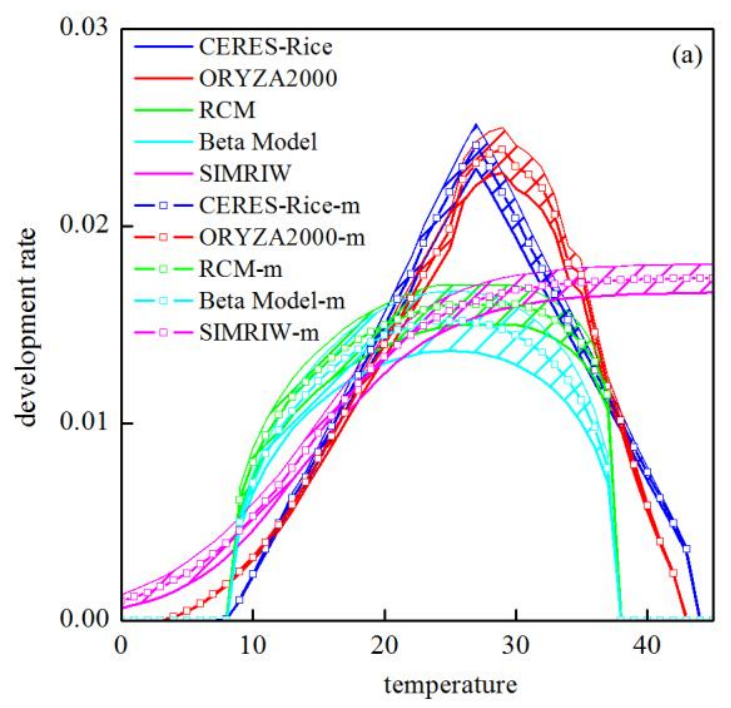

Figr-5

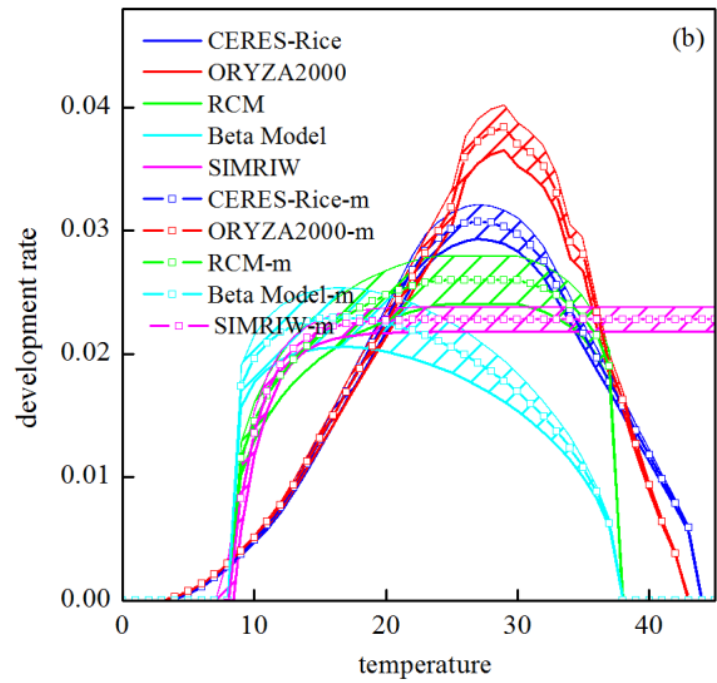

Fig.5. Relationship between rice development rate and temperature for the five models with 50 sets of parameters in zone I. (a) heading date simulated by the five models with their respective 50 sets of parameters; (b) maturity simulated by the five models with their respective 50 sets of parameters. 

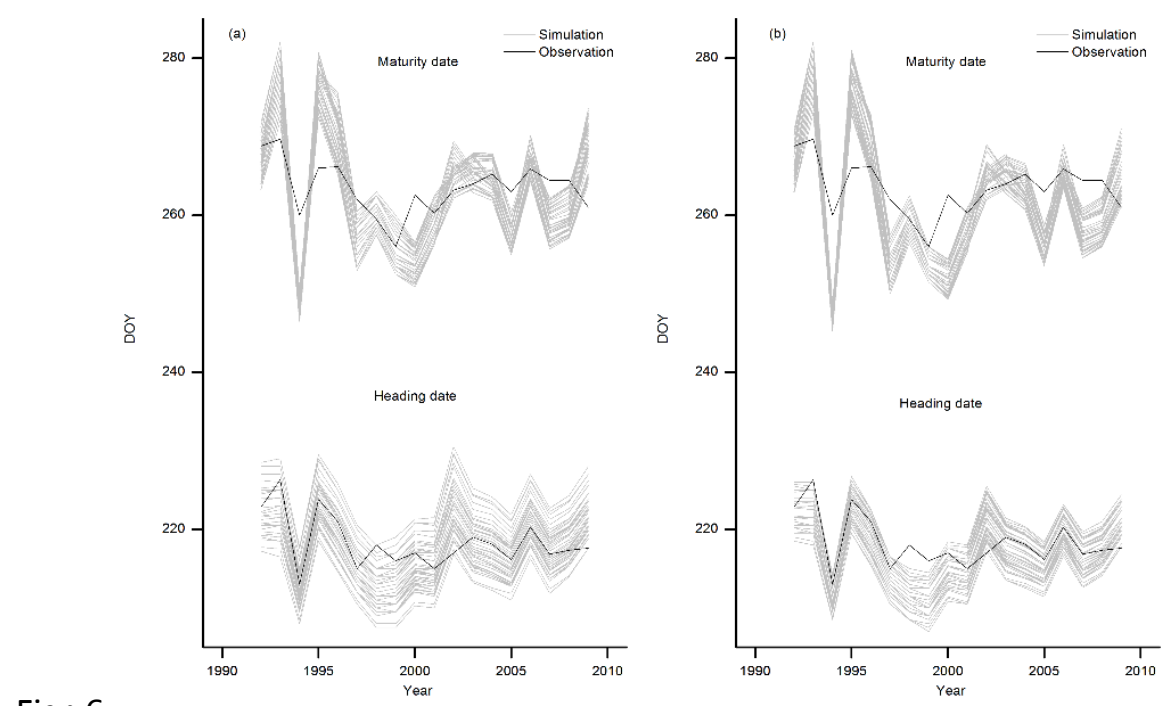

Figr-6
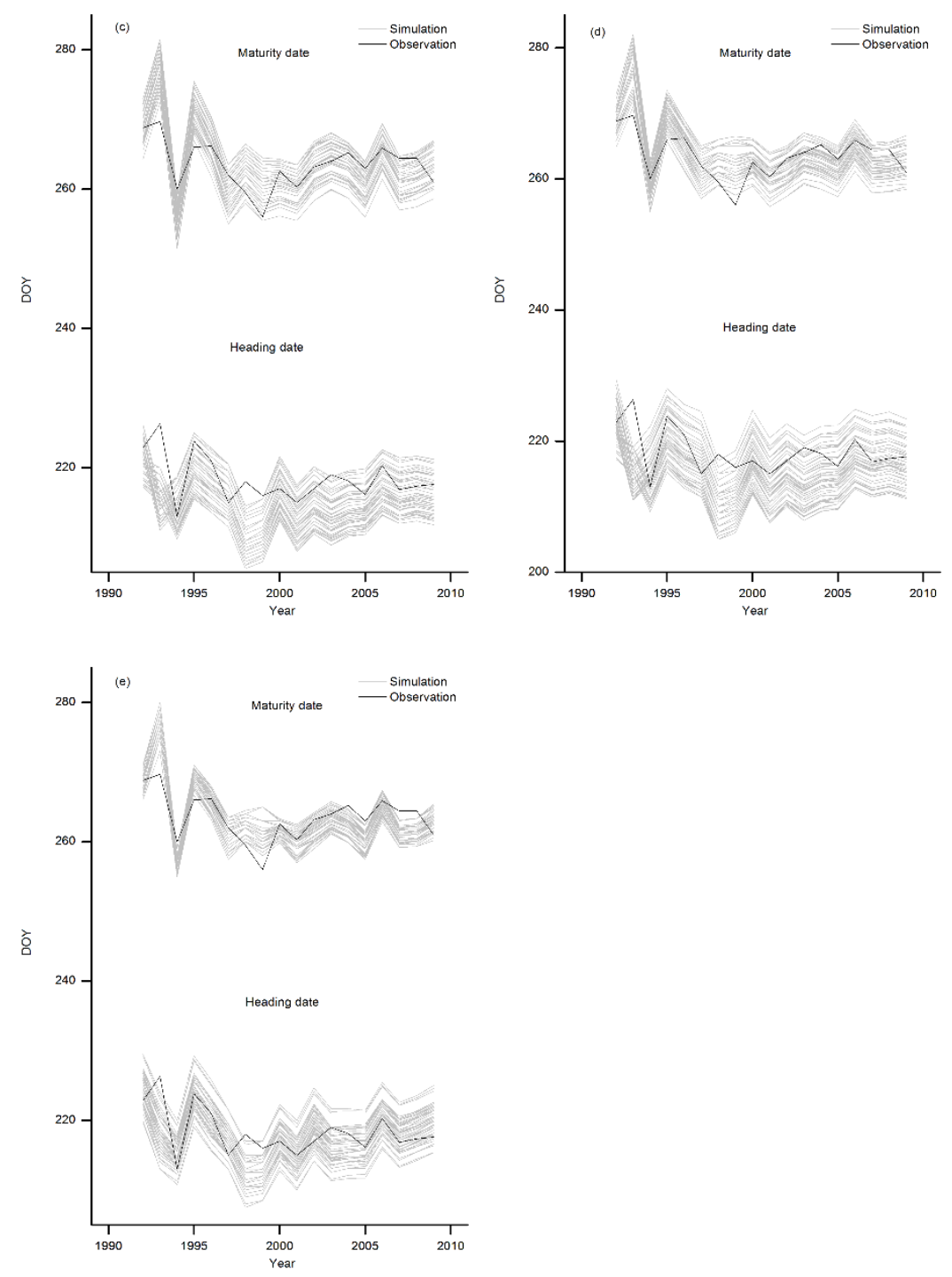

Fig.6. Simulated rice heading dates and maturity dates by the (a) CERES-Rice, (b) ORYZA2000, (c) RCM, (d) Beta Model, (e) SIMRIW with 50 sets of parameters in zone I. 
Figr-7

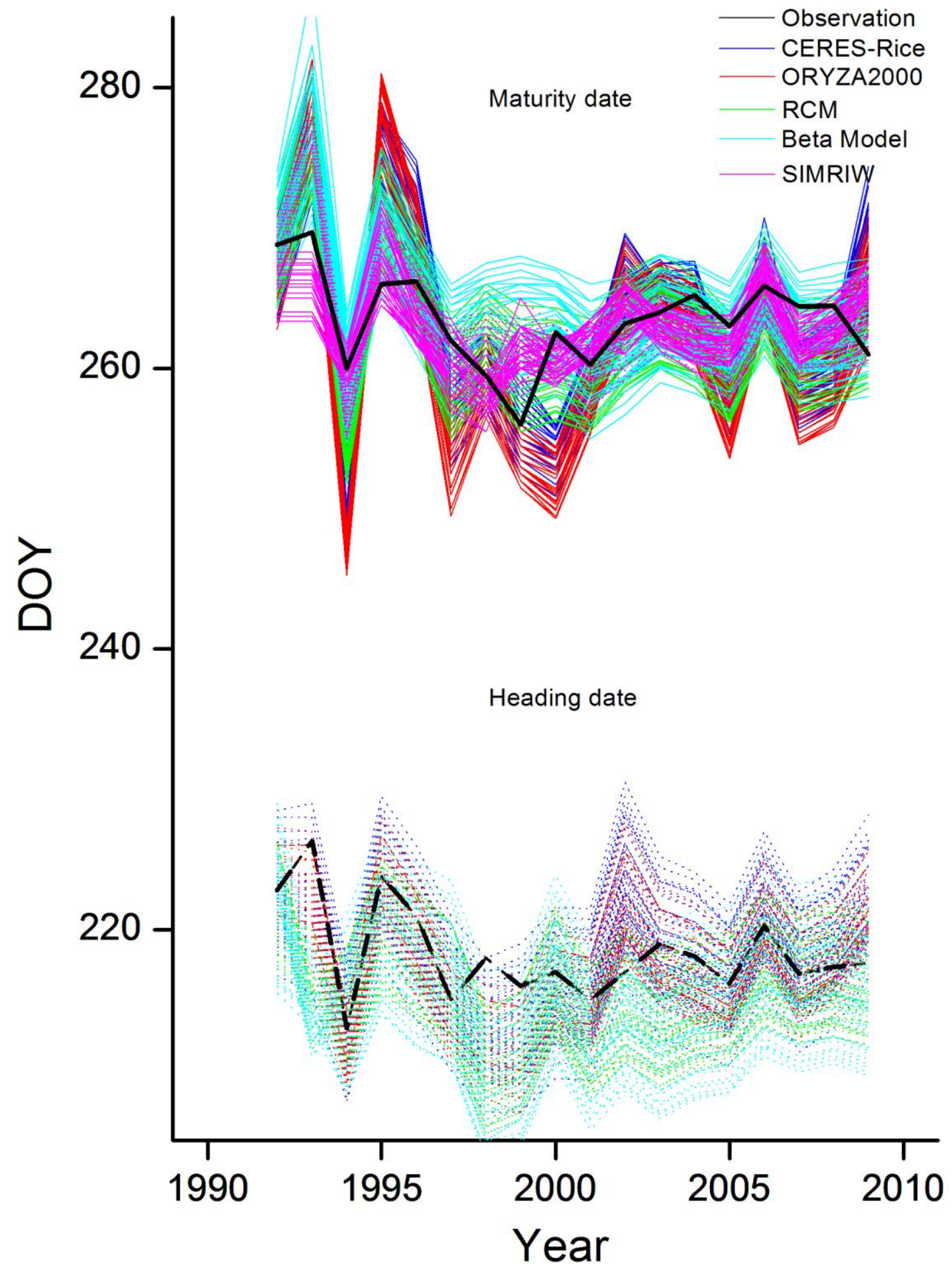

Fig.7. Simulated rice heading dates and maturity dates by the five models with their respective 50 sets of perturbed parameters in zone I. 


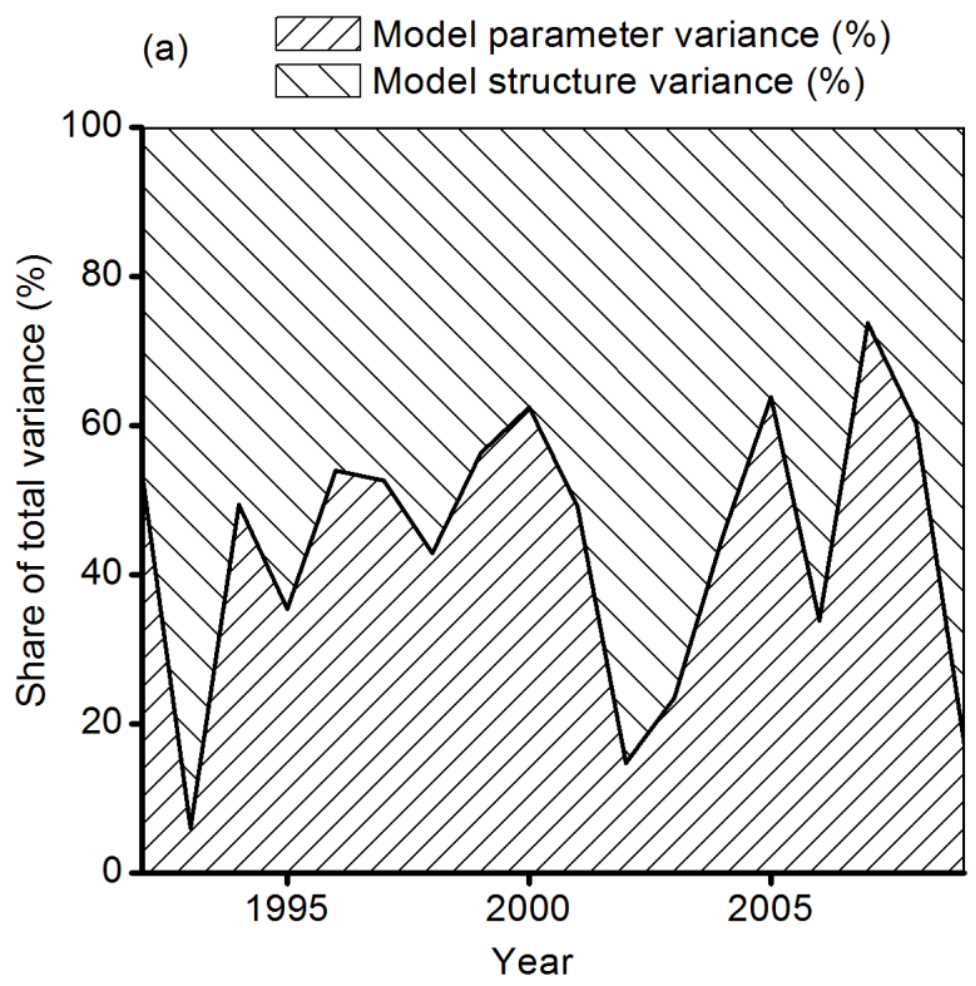

Figr-8

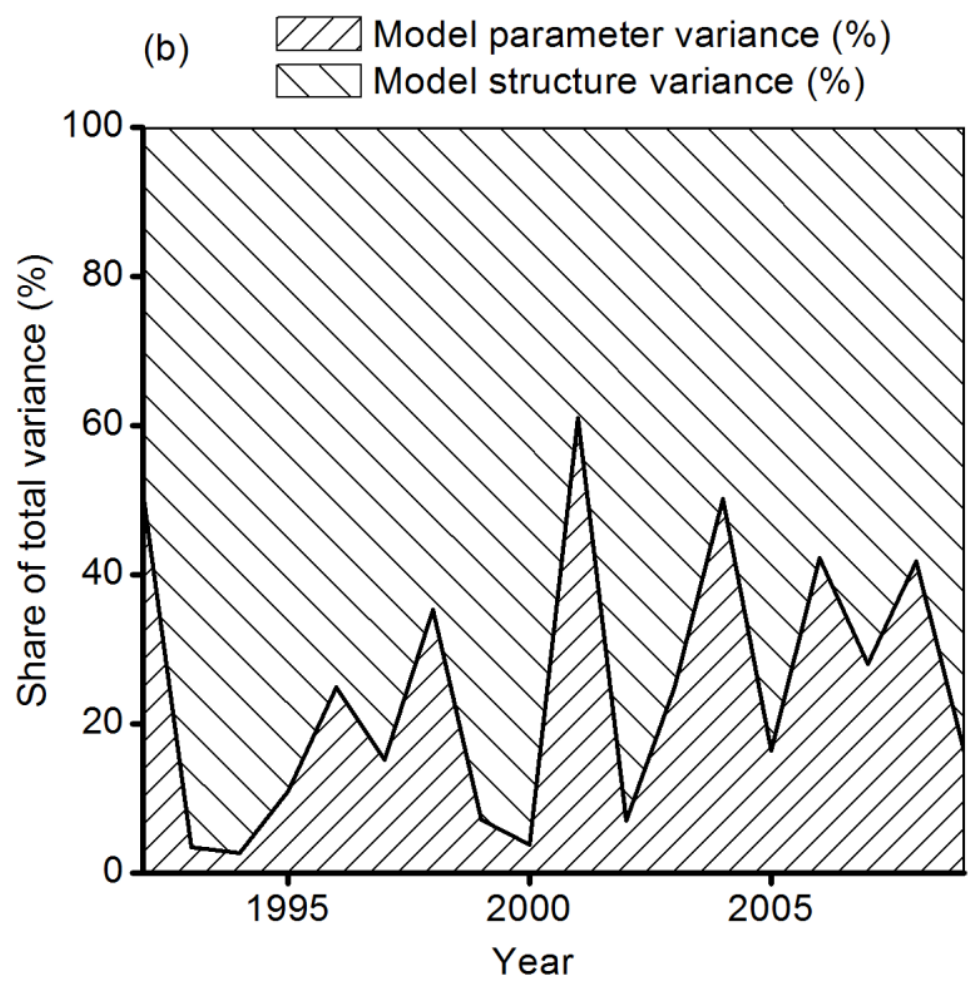

Fig.8. Share of the model total variance from model structure and model parameters in simulating rice heading date (a) and maturity date (b) in zone I. 


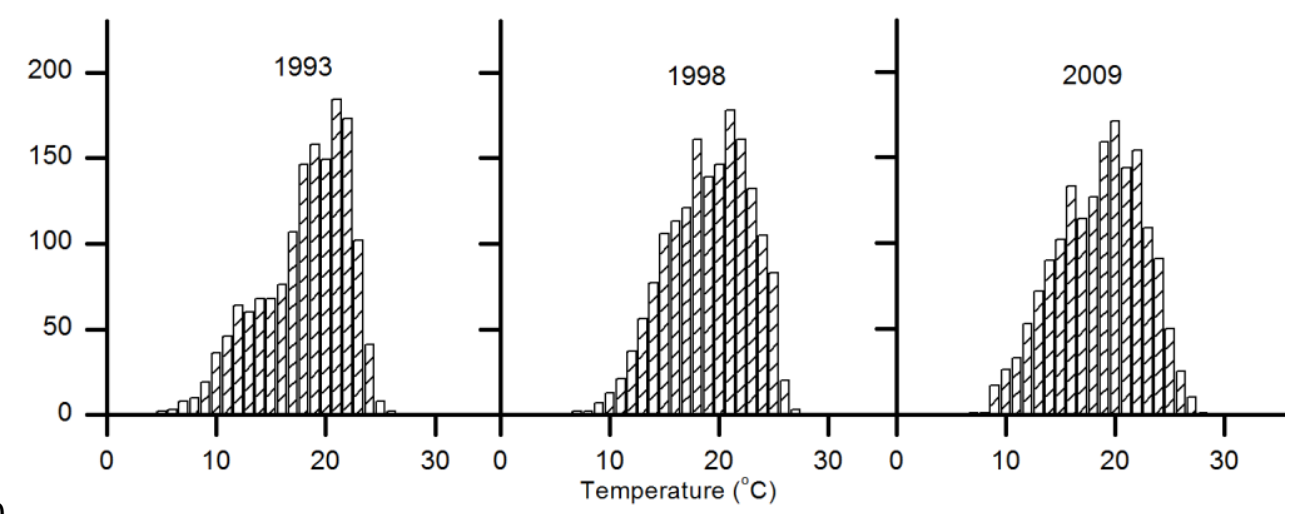

Figr-9

Fig.9. Frequency distribution of temperatures in 1993, 1998, and 2009 during rice growing period in zone I. 
Table 1 Statistic on the simulations using the five models with their respective one set of optimal parameters and 50 sets of perturbed parameters

\begin{tabular}{|c|c|c|c|c|c|c|c|}
\hline \multirow[t]{2}{*}{ Model } & \multirow[t]{2}{*}{ stage } & \multirow[t]{2}{*}{ parameters } & \multirow[t]{2}{*}{ Description } & \multicolumn{2}{|c|}{ Zone I } & \multicolumn{2}{|c|}{ Zone II } \\
\hline & & & & $\begin{array}{l}\text { optimal } \\
\text { value }\end{array}$ & $\begin{array}{l}\text { repeturtion } \\
\text { range }\end{array}$ & $\begin{array}{l}\text { optimal } \\
\text { value }\end{array}$ & $\begin{array}{l}\text { repeturtion } \\
\text { range }\end{array}$ \\
\hline \multirow{4}{*}{ CERES-Rice } & \multirow{3}{*}{ VGP } & P1 & $\begin{array}{l}\text { the threshold of DTT } \\
\text { for VGP }\end{array}$ & 776.00 & $\begin{array}{l}737.20- \\
814.80\end{array}$ & 1060.00 & $\begin{array}{c}1007.00- \\
1113.00\end{array}$ \\
\hline & & $\mathrm{DL}_{\mathrm{c}}$ & critical day length & 15.11 & $\begin{array}{c}14.355- \\
15.866\end{array}$ & 15.11 & $\begin{array}{l}14.355- \\
15.866\end{array}$ \\
\hline & & $\mathrm{P} 2 \mathrm{R}$ & $\begin{array}{l}\text { photoperiod } \\
\text { sensitivity parameter }\end{array}$ & 12.81 & $\begin{array}{l}12.17- \\
13.451\end{array}$ & 12.81 & $\begin{array}{l}12.17- \\
13.451\end{array}$ \\
\hline & RGP & P5 & $\begin{array}{l}\text { the threshold of DTT } \\
\text { for RGP }\end{array}$ & 510.00 & $\begin{array}{c}484.50- \\
535.50\end{array}$ & 550.00 & $\begin{array}{c}522.50- \\
577.50\end{array}$ \\
\hline \multirow{4}{*}{ ORYZA2000 } & \multirow{3}{*}{ VGP } & DVRI & $\begin{array}{l}\text { the threshold of } \\
\text { DTU accumulation } \\
\text { for VGP }\end{array}$ & 858.00 & $\begin{array}{c}815.1- \\
900.9\end{array}$ & 1200.00 & $\begin{array}{l}1140.00- \\
1240.00\end{array}$ \\
\hline & & PPSE & $\begin{array}{l}\text { photoperiod } \\
\text { sensitivity parameter }\end{array}$ & 0.05 & $\begin{array}{c}0.0475- \\
0.0525\end{array}$ & 0.08 & $\begin{array}{l}0.076- \\
0.084\end{array}$ \\
\hline & & $\mathrm{DL}_{\mathrm{c}}$ & critical day length & 12.50 & $\begin{array}{c}11.875- \\
13.125 \\
\end{array}$ & 12.00 & $\begin{array}{c}11.40- \\
12.40 \\
\end{array}$ \\
\hline & RGP & DVRR & $\begin{array}{l}\text { the threshold of } \\
\text { DTU accumulation } \\
\text { for RGP }\end{array}$ & 535.00 & $\begin{array}{c}508.25- \\
561.75\end{array}$ & 570.00 & $\begin{array}{c}541.50- \\
598.50\end{array}$ \\
\hline \multirow{8}{*}{$\mathrm{RCM}$} & \multirow{5}{*}{ VGP } & $\mathrm{k}$ & empirical constants & 12.60 & $\begin{array}{c}12.30- \\
13.00\end{array}$ & 12.00 & $\begin{array}{c}11.40- \\
12.60\end{array}$ \\
\hline & & $\mathrm{P}$ & empirical constants & -4.136 & $\begin{array}{l}-4.2028-- \\
4.0692\end{array}$ & -4.24 & $\begin{array}{l}-4.312-- \\
4.178\end{array}$ \\
\hline & & Q & empirical constants & 0.406 & $\begin{array}{c}0.3907- \\
0.4163\end{array}$ & 0.35 & $\begin{array}{c}0.3325- \\
0.3675\end{array}$ \\
\hline & & G & empirical constants & 0.216 & $\begin{array}{c}0.2052- \\
0.2268\end{array}$ & 0.20 & $0.19-0.21$ \\
\hline & & $\mathrm{DL}_{\mathrm{c}}$ & critical day length & -0.022 & $\begin{array}{c}-0.0231-- \\
0.0209\end{array}$ & -0.02 & $\begin{array}{c}-0.021-- \\
0.019\end{array}$ \\
\hline & \multirow{3}{*}{ RGP } & $\mathrm{k}$ & empirical constants & -3.65 & $\begin{array}{l}-3.7325-- \\
3.5675\end{array}$ & -3.365 & $\begin{array}{c}-3.5333-- \\
3.2968\end{array}$ \\
\hline & & $\mathrm{P}$ & empirical constants & 0.35 & $\begin{array}{c}0.3325- \\
0.3675\end{array}$ & 0.45 & $\begin{array}{c}0.4275- \\
0.4725\end{array}$ \\
\hline & & $\mathrm{Q}$ & empirical constants & -6.55 & $\begin{array}{c}-6.57-- \\
6.53\end{array}$ & -7.91 & $\begin{array}{c}-7.93-- \\
7.89\end{array}$ \\
\hline \multirow{5}{*}{ Beta Model } & \multirow{5}{*}{ VGP } & $\mu$ & empirical constants & 0.50 & $\begin{array}{c}0.475- \\
0.525\end{array}$ & 0.95 & $0.93-0.98$ \\
\hline & & $\alpha$ & empirical constants & 0.369 & $\begin{array}{c}0.3505- \\
0.3875\end{array}$ & 0.37 & $\begin{array}{l}0.3515- \\
0.3885\end{array}$ \\
\hline & & $\beta$ & empirical constants & -5.743 & $\begin{array}{c}-5.78-- \\
5.71\end{array}$ & -4.80 & $-4.82--4.78$ \\
\hline & & $\delta$ & empirical constants & 0.20 & $0.19-0.21$ & 0.20 & $0.19-0.21$ \\
\hline & & $\varepsilon$ & empirical constants & 0.50 & $\begin{array}{c}0.475- \\
0.525\end{array}$ & 0.30 & $\begin{array}{l}0.285- \\
0.315\end{array}$ \\
\hline
\end{tabular}




\begin{tabular}{|c|c|c|c|c|c|c|c|}
\hline & \multirow{3}{*}{ RGP } & $\mu$ & empirical constants & 0.90 & $0.88-0.92$ & 0.70 & $\begin{array}{l}0.665- \\
0.735\end{array}$ \\
\hline & & $\alpha$ & empirical constants & 20.55 & $19.5-21.5$ & 22.15 & $\begin{array}{l}21.043- \\
23.258\end{array}$ \\
\hline & & $\beta$ & empirical constants & 57.01 & $\begin{array}{c}55.00- \\
60.00\end{array}$ & 60.03 & $\begin{array}{l}56.529- \\
63.532\end{array}$ \\
\hline \multirow{8}{*}{ SIMRIW } & \multirow{5}{*}{ VGP } & $\mathrm{DL}_{\mathrm{c}}$ & critical day length & 0.20 & $0.18-0.23$ & 0.28 & $\begin{array}{l}0.266- \\
0.294\end{array}$ \\
\hline & & $\mathrm{T}_{\mathrm{h}}$ & $\begin{array}{l}\text { the temperature at } \\
\text { which DVR is half } \\
\text { the maximum rate at } \\
\text { the optimum } \\
\text { temperature }\end{array}$ & 13.96 & $13.5-14.5$ & 20.31 & $\begin{array}{l}19.294- \\
21.326\end{array}$ \\
\hline & & $\mathrm{G}_{\mathrm{v}}$ & $\begin{array}{l}\text { the minimum } \\
\text { number of days } \\
\text { required for heading }\end{array}$ & 0.94 & $\begin{array}{c}0.893- \\
0.987\end{array}$ & 0.58 & $\begin{array}{c}0.551- \\
0.609\end{array}$ \\
\hline & & A & empirical constants & 0.47 & $\begin{array}{c}0.4465- \\
0.4935\end{array}$ & 0.11 & $\begin{array}{l}0.1045- \\
0.1155\end{array}$ \\
\hline & & B & empirical constants & 8.00 & $7.60-8.40$ & 10.00 & $9.5-10.5$ \\
\hline & \multirow{3}{*}{ RGP } & $\mathrm{G}_{\mathrm{r}}$ & $\begin{array}{l}\text { the minimum } \\
\text { number of days for } \\
\text { grain-filling period }\end{array}$ & 44.00 & $\begin{array}{c}41.80- \\
46.20\end{array}$ & 25.00 & $\begin{array}{l}23.75- \\
26.25\end{array}$ \\
\hline & & $\mathrm{K}_{\mathrm{r}}$ & empirical constants & 776.00 & $\begin{array}{c}737.20- \\
814.80\end{array}$ & 1060.00 & $1007-1113$ \\
\hline & & $\mathrm{T}_{\mathrm{cr}}$ & empirical constants & 15.11 & $\begin{array}{c}14.355- \\
15.866\end{array}$ & 15.11 & $\begin{array}{c}14.355- \\
15.866\end{array}$ \\
\hline
\end{tabular}


Table2 Statistic on the simulations using the five models with their respective one set of optimal parameters and 50 sets of perturbed parameters

\begin{tabular}{|c|c|c|c|c|c|c|c|c|c|c|c|c|}
\hline & & \multicolumn{6}{|c|}{ Zone I } & \multicolumn{5}{|c|}{ Zone II } \\
\hline & & \multicolumn{3}{|c|}{ Heading date } & \multicolumn{3}{|c|}{ Maturity date } & \multicolumn{3}{|c|}{ Heading date } & \multicolumn{2}{|c|}{ Maturity da } \\
\hline & & $\begin{array}{l}\text { RMSE } \\
\text { (days) }\end{array}$ & $r$ & $\begin{array}{c}\text { Bias } \\
\text { (days) }\end{array}$ & $\begin{array}{l}\text { RMSE } \\
\text { (days) }\end{array}$ & $\mathrm{R}$ & $\begin{array}{c}\text { Bias } \\
\text { (days) }\end{array}$ & $\begin{array}{l}\text { RMSE } \\
\text { (days) }\end{array}$ & $\mathrm{r}$ & $\begin{array}{c}\text { Bias } \\
\text { (days) }\end{array}$ & $\begin{array}{l}\text { RMSE } \\
\text { (days) }\end{array}$ & $\mathrm{r}$ \\
\hline One & CERES-Rice & 6.70 & 0.27 & 0.02 & 8.71 & 0.53 & -1.28 & 7.08 & 0.82 & -0.20 & 4.97 & 0.94 \\
\hline Model & ORYZA2000 & 6.62 & 0.30 & -0.77 & 9.12 & 0.54 & -2.50 & 7.78 & 0.81 & 2.81 & 5.42 & 0.94 \\
\hline with one & $\mathrm{RCM}$ & 6.09 & 0.30 & -1.89 & 4.81 & 0.66 & -1.31 & 8.60 & 0.80 & -0.93 & 4.56 & 0.94 \\
\hline set of & Beta Model & 6.45 & 0.29 & -2.59 & 4.33 & 0.66 & -0.46 & 7.62 & 0.82 & -0.81 & 5.17 & 0.93 \\
\hline parameters & SIMRIW & 6.36 & 0.27 & -0.76 & 4.44 & 0.67 & -1.26 & 7.90 & 0.84 & 4.06 & 4.89 & 0.94 \\
\hline One & CERES-Rice & 6.70 & 0.27 & -0.23 & 8.89 & 0.52 & -0.86 & 7.15 & 0.81 & -0.61 & 4.90 & 0.94 \\
\hline Model & ORYZA2000 & 6.73 & 0.30 & -1.46 & 6.71 & 0.60 & 0.31 & 7.64 & 0.81 & 2.23 & 4.70 & 0.94 \\
\hline with 50 & $\mathrm{RCM}$ & 6.63 & 0.29 & -3.18 & 5.28 & 0.66 & 2.41 & 8.58 & 0.80 & -0.42 & 4.58 & 0.94 \\
\hline sets of & Beta Model & 6.49 & 0.30 & -2.78 & 4.23 & 0.66 & -0.40 & 8.23 & 0.82 & -3.33 & 5.18 & 0.93 \\
\hline parameters & SIMRIW & 6.26 & 0.28 & -0.12 & 4.46 & 0.66 & -1.08 & 8.42 & 0.84 & 5.00 & 4.83 & 0.94 \\
\hline $\begin{array}{c}\text { Five } \\
\text { Models } \\
\text { with one } \\
\text { set of } \\
\text { parameters }\end{array}$ & & 5.86 & 0.34 & -0.83 & 4.81 & 0.65 & -1.36 & 6.74 & 0.86 & 1.24 & 4.67 & 0.94 \\
\hline $\begin{array}{c}\text { Five } \\
\text { Model } \\
\text { with } 50 \\
\text { sets of } \\
\text { parameters }\end{array}$ & & 6.36 & 0.28 & -1.23 & 5.13 & 0.63 & 0.47 & 7.40 & 0.81 & 0.37 & 4.66 & 0.94 \\
\hline
\end{tabular}

